\title{
Perspectivas internacionais: os ventos favoráveis que sopram de Espanha e a experiência dos Seminários de Inovação em Cuidados de Saúde Primários (SICSP)
}

Tiago Villanueva,* Juan Gérvas, ${ }^{* *}$ Sergio Minué***

\section{RESUMO}

Os Seminários de Inovação em Cuidados de Saúde Primários são uma iniciativa ímpar no panorama europeu, da responsabilidade de três organizações espanholas, coordenadas por um médico de Clínica Geral. Nestes seminários analisam-se as últimas tendências e inovações no âmbito da organização de serviços de saúde, da investigação clínica, bem como as questões principais que irão caracterizar a Medicina Geral e Familiar no século XXI.

Esta actividade tem interesse para os médicos portugueses de Medicina Geral e Familiar e é relevante para os internos da especialidade, dado o grande enriquecimento pessoal em termos de produção de conhecimento que proporciona e o contacto que permite com uma dinâmica rede multidisciplinar espanhola de profissionais dos cuidados de saúde.

Palavras-chave: Espanha; Medicina Geral; Inovação; Rede; Seminários.

\section{INTRODUÇÃO}

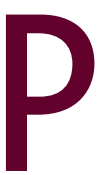

ortugal e Espanha entraram no mesmo ano, em 1986, para o que era então conhecido como Comunidade Económica Europeia (CEE). Na altura, ambos os países se encontravam bastante mais atrasados do que hoje em relação aos países mais avançados da Europa. Nesse ano, existia já a especialidade de Medicina Geral e Familiar (MGF) tanto em Portugal como em Espanha (designada, em Espanha, por Medicina Familiar y Comunitária).

\footnotetext{
*Médico Interno de Medicina Geral e Familiar, USF AlphaMouro, Rio de Mouro ** Licenciado y doctor en Medicina, médico general rural de Canencia de la Sierra, Garganta de los Montes y El Cuadrón (Madrid, Espanha), Equipo CESCA (Madrid), Profesor de Salud Internacional (Escuela Nacional de Sanidad) y Salud Pública (Facultad de Medicina, Universidad Autónoma, Madrid). www.equipocesca.org ***Médico especialista en Medicina de Familia, Profesor de Atención Primaria y Director de Gestión de la Práctica Asistencial. Escuela Andaluza de Salud Pública. Granada (España)
}

Findos quase 25 anos, Portugal e Espanha conheceram destinos bem diferentes. Ao contrário de Portugal, Espanha foi bem sucedida em atingir a tão falada convergência com o nível médio de vida europeu: as últimas estatísticas do Eurostat mostram que o PIB per capita em Espanha é, actualmente, de cerca de 105\% da média da União Europeia a 27. ${ }^{1}$ Para além disso, Espanha já se encontra à frente de países como o Reino Unido ou a Itália, no ranking do Îndice de Desenvolvimento Humano. ${ }^{2}$ Por outro lado, e em contraste com Portugal, a MGF em Espanha conheceu circunstâncias políticas particulares durante os anos 70. Os primeiros governos democráticos, a partir de 1975, quiseram apostar em cuidados de saúde primários de qualidade, levando à reforma de 1984, que se traduziu num aumento dos recursos materiais, humanos e financeiros. ${ }^{3}$ Para além disso, apoiou-se a investigação em todas as 
áreas da saúde, incluindo os cuidados de saúde primários. Os financiamentos dos projectos dos cuidados de saúde primários acabavam por competir directamente com os hospitais e as universidades em pé de igualdade. Muitos médicos de família espanhóis beneficiaram de vários tipos de apoio para realizarem estágios em universidades e centros estrangeiros de referência, desde Cuba aos Estados Unidos. Tudo isto gerou uma dinâmica que se mantém, quase 30 anos depois, e que acaba por alimentar uma cultura de inovação e levar à melhoria do trabalho clínico e de gestão.

No entanto, apesar de um contexto aparentemente favorável, nem tudo é cor-de-rosa. Por exemplo, apesar do orçamento dos cuidados de saúde primários ter vindo a aumentar em números absolutos, apenas representa $16 \%$ do total; ${ }^{3}$ por outro lado, a especialidade de MGF é a menos popular entre os médicos internos. Contudo, a MGF espanhola é considerada a quarta melhor do mundo, depois da inglesa, da holandesa e da dinamarquesa. ${ }^{4}$ Os Seminários de Inovação em Cuidados de Saúde Primários (SICSP) constituem-se, precisamente, como uma expressão da vitalidade da MGF espanhola, assente num núcleo de profissionais provenientes de diferentes contextos de prática, capazes de questionar, pela positiva, o seu trabalho e o fundamento científico em que assenta a organização da prática clínica.

\section{ORGANIZAÇÃO DOS SICSP}

Os Seminários são organizados conjuntamente por três fundações espanholas, a Fundación de Ciencias de la Salud, a Fundación para la Formación de la Organización Médica Colegial (OMC, a Ordem dos Médicos espanhola) e a Fundação Jordi Gol (através do seu Instituto de Investigação em Cuidados de Saúde Primários, em Barcelona). As duas primeiras fundações arrancaram com esta experiência em 2005, à qual se juntou a fundação catalã em 2007. O financiamento tem estado a cargo do Ministério da Saúde espanhol (em 2005 e 2007, 2008) e do laboratório Glaxo SmithKline. O Dr. Juan Gérvas tem sido o dinamizador dos SICSP, coordenando um grupo de trabalho constituído por cerca de 50 pessoas.

\section{MODELO DE TRABALHO DOS SICSP}

O funcionamento dos seminários obedece a um modelo conhecido como «rede não orgânica»; ou seja, ape- sar de os membros serem membros de organizações sanitárias e académicas, maioritariamente públicas, participam nos Seminários a título exclusivamente individual, como peritos numa determinada área. O grupo possui as características essenciais de uma rede, flexibilidade, adaptabilidade e capacidade de auto-regulação. A participação no trabalho do grupo praticamente não exige burocracia e há lugar à liberdade intelectual de cada um. É de salientar que o acesso individual ao grupo não é livre, sendo o principal critério de aceitação o reconhecimento de méritos pelos seus pares, relativamente a uma determinada matéria.

A participação de médicos internos nos SICSP tem como finalidade a redução do tempo de impacto do seu trabalho na comunidade científica de cuidados de saúde primários. Isto significa que os médicos internos de MGF têm, assim, a oportunidade de se integrar como pares entre os participantes e os prelectores dos SICSP, através da partilha de conhecimentos e do estabelecimento de relações pessoais com as «autoridades científicas» no âmbito da investigação, docência, clínica e gestão em cuidados de saúde primários. Assim, as próprias ideias dos médicos internos acabam por chegar e «dar-se a conhecer» aos autores conhecidos e consagrados, ao mesmo tempo que aprendem ao vivo e vão recebendo o testemunho dos seus colegas mais velhos.

\section{PERFIS DOS PARTICIPANTES}

Embora os médicos sejam predominantes, os participantes nos seminários pertencem a um largo espectro de classes profissionais: participam, também, farmacêuticos, enfermeiros, engenheiros, sociólogos e economistas. É de realçar que os profissionais do meio rural se encontram largamente representados. As idades e nível de experiência são, também, variadas.

Assim, o leque profissional dos participantes é constituído por quatro grupos: o clínico (médicos especialistas e internos de MGF e medicina preventiva), o de gestão (profissionais que trabalham em departamentos de gestão de saúde, maioritariamente públicos), académico (professores de universidades e professores de escolas de saúde pública) e o profissional (sociedades científicas, colégios profissionais e sindicatos).

\section{OBJECTIVOS DOS SICSP}

A realização dos seminários procura alcançar três gran- 
des objectivos. O primeiro é analisar as mudanças inovadoras que ocorrem no âmbito dos CSP; o segundo é disseminar essas mesmas inovações e o terceiro é sensibilizar e chamar a atenção para o desenvolvimento de novas ideias. Parte-se do princípio que as experiências discutidas e analisadas possam ajudar no processo de tomada de decisões, caso se faça um esforço para as tomar em consideração, independentemente do contexto.

Isto significa que as experiências de inovação se desenrolam em circunstâncias e momentos concretos, mas acabam sempre por ter uma «leitura» universal enquanto geradoras de ideias, para além de servirem de estímulo para analisar os problemas de uma forma diferente.

Em 2005, os seminários incidiram sobre «A coordenação entre os cuidados de saúde primários e os cuidados especializados». Em 2006, o tema foi «A capacidade resolutiva dos cuidados de saúde primários»; em 2007 foi sobre «A Organização dos cuidados de saúde primários»; em 2008 discutiram-se «Os limites da prevenção clínica»e, em 2009, «O processo diagnóstico em cuidados de saúde primários».

\section{METODOLOGIA DE TRABALHO}

Existe uma série de três a quatro seminários presenciais, por ano, desde 2005, relativos a um assunto com especial interesse. Em 2008 houve três, e em 2009 também haverá três. Cada seminário é conduzido por um conferencista, que, por regra, é um especialista no tema em causa. Ultimamente, os seminários têm evoluído para um modelo com 3 animadores. Para além do prelector, outros dois especialistas apresentam o seu «contraponto», local e clínico, respectivamente, o que acaba por complementar e enriquecer a visão sobre o tema que está a ser discutido.

Cerca de duas semanas antes do seminário presencial, os participantes recebem, por correio electrónico, as apresentações escritas dos vários prelectores, com a descrição e a análise da experiência inovadora, bem como as perguntas abertas que serão discutidas no Seminário presencial. Durante os 15 dias que antecedem o seminário presencial, prevê-se que os participantes comentem os textos e façam perguntas perante todo o grupo que consta na lista electrónica. O seminário presencial desenrola-se ao longo de 6 horas, em Madrid, e está dividido em duas partes: 1) exposição acerca da inovação, proferida pelos conferencistas; 2) discussão aberta a todos os participantes sobre as perguntas lançadas no documento inicial. O lugar de realização deste evento tem sido sempre a sede da Organizacion Médica Colegial, a Ordem dos Médicos espanhola, no centro da capital espanhola.

Terminado o seminário, os conferencistas procedem a modificações nos seus textos, com base no feedback recebido. O novo texto é, posteriormente, difundido por todos os participantes na Internet. Mais tarde, é redigido um texto com vista a publicação, numa revista com revisão por pares, e é organizada uma monografia congregando todas as apresentações dos seminários de um determinado ano.

\section{FACTORES DECISIVOS PARA O SUCESSO DOS SICSP E RESULTADOS EMTERMOS DE PUBLICAÇÕES}

A estabilidade e o sucesso do trabalho do grupo podem-se atribuir ao seguinte conjunto de factores: a adopção do trabalho em rede como estratégia; a existência de uma partilha de valores, nomeadamente o compromisso com os cuidados de saúde primários; o respeito mútuo e a definição explícita das regras do jogo; a existência de uma liderança forte, reconhecida e aceite; $o$ acesso ao grupo com base no mérito profissional, particularmente o tipo de publicações e a participação em experiências inovadoras; um nível elevado de participação activa para assegurar a manutenção no grupo; a existência de um objectivo claro de se publicar os artigos produzidos; a existência regular de patrocínio e apoios institucionais; a heterogeneidade de pontos de vista e de experiências pessoais; a utilização de novas tecnologias como complemento das actividades presenciais.

Até à data, Março de 2009, realizaram-se 16 seminários, de que resultaram já, três monografias publicadas (há uma outra no prelo) e 18 artigos publicados em revistas científicas de prestígio (por exemplo, Gérvas J, Starfield B, Violán C, Minué S. GPs with special interests. Unanswered questions. Br J Gen Pract 2007; 57: 912-7).

\section{PORQUE É QUE OS SICSP TÊM INTERESSE E IMPORTÂNCIA PARA OS INTERNOS DE MGF PORTUGUESES?}

Os SICSP constituem uma rara oportunidade de desen- 
volvimento profissional para os internos de MGF, nomeadamente por implicarem, não só a leitura e análise de textos complexos como, também, pelo contacto com proeminentes figuras da MGF espanhola e mundial, sobretudo através da componente presencial dos seminários. A leitura e a análise dos textos escritos pelos conferencistas, apresentados e discutidos posteriormente nos seminários, permite aos internos adquirir conhecimentos numa série de matérias não clínicas, que, normalmente, não fazem parte do programa do curso de medicina e do internato de MGF. Também permite afinar as suas competências de julgamento crítico da literatura, o que só pode ajudar a ser-se um melhor médico e a ter maior preparação para assumir, mais tarde, funções de liderança, gestão ou cargos de responsabilidade. Por outro lado, os SICSP possibilitam o estabelecimento de uma rede multidisciplinar internacional de contactos que podem revelar-se de enorme utilidade ao longo da vida profissional do médico interno (sobretudo agora, que o internato tem quatro anos de duração) e do futuro especialista, porque o contacto pode manter-se e, inclusivamente, aprofundar-se para além dos seminários. Assim, é fundamental que o interno possa conhecer pessoalmente os outros membros do grupo dos SICSP, a fim de potenciar ao máximo os efeitos do «networking» intenso que os seminários proporcionam.

Os SICSP dão uma visão acerca da organização dos serviços de saúde, sobre a investigação clínica e sobre as questões-chave que irão permear a MGF do século XXI. Os seminários complementam e enriquecem muito o internato, porque permitem ao participante ganhar uma percepção mais abrangente sobre o que são realmente os CSP, para além do enfoque tradicional na clínica, nomeadamente no aspecto social, económico, político. Em termos práticos, é natural que não vão ajudar muito o interno a superar os exames que se centram na componente clínica, e que acabem por ter pouca valorização curricular. Contudo, os seminários têm um valor intrínseco que transcende o internato e fornecem um grau adicional de preparação científica, que irá permitir enfrentar melhor os desafios profissionais do futuro.

O médico interno português tem, com os SICSP, uma forma de acesso fácil a um tipo de conhecimento que não se cinge aos aspectos do fazer imediatista clínico, que provém de fontes de prestígio preocupadas com os porquês e com os valores intrínsecos da medicina. Por exemplo, em 2008, discutiu-se o tema «Os limites da prevenção", podendo o médico interno abordar questões com as quais não está muito familiarizado, como por exemplo, o estabelecimento de prioridades e o impacto da prevenção no papel profissional do médico.

\section{LIÇÕES A RETIRAR DOS SICSP PARA OS INTERNOS DE MGF PORTUGUESES E PARA A MGF PORTUGUESA}

A primeira lição a retirar é o elevado nível académico da MGF espanhola. Este nível é conseguido mediante a reunião de alguns dos melhores profissionais e académicos de renome nacional e internacional, nas suas respectivas áreas, em torno de uma agenda comum. Para reforçar o calibre intelectual dos seminários, Barbara Starfield ou Iona Heath são uma presença regular. Por isso, a participação de médicos de MGF portugueses deve ser encarada como positiva, uma vez que permite a ampliação da rede de contactos profissionais internacionais, o que se espera possa trazer benefícios subsequentes para a MGF nacional.

A segunda lição é a importância de se conseguir um debate multidisciplinar, dada a presença de várias classes de profissionais de saúde para além de médicos, o que não acontece com frequência na realidade nacional, pelo menos com este espírito de abertura e participação. As discussões tornam-se, assim, mais ricas, permitindo a aprendizagem de perspectivas diferentes da medicina.

A terceira é a obtenção de resultados tangíveis. Efectivamente, os seminários constituem um autêntico viveiro de produção científica, através dos quais é possível, posteriormente, condensar e estruturar todas as ideias apresentadas num artigo que possa ser enviado para uma revista indexada de prestígio.

Será possível estabelecer em Portugal um projecto semelhante? Provavelmente sim, mas com maior dificuldade, uma vez que Portugal tem uma menor dimensão do que Espanha. Neste sentido julgamos mais exequível alargar esta experiência a Portugal. Porém, o grupo dos SICSP é fechado, e como tal, a admissão de novos membros é condicionada. Os interessados podem entrar em contacto com o Dr. Gérvas manifestando o seu interesse pessoal e motivação em participar nos se- 
minários. Para o efeito devem juntar um breve Curriculum Vitae. Pode ser obtida informação adicional no endereço electrónico da Fundación de Ciencias de la Salud (http://www.fcs.es).

\section{CONCLUSÕES}

A actividade científica despoletada pelos seminários tem-se saldado por um número significativo de publicações científicas em revisões por pares. Em quatro anos foram publicados 21 .

Para além dos resultados tangíveis, esta experiência propicia a geração de conhecimento tácito, quer no aspecto da partilha de experiências pessoais, que de outra forma seria impossível conhecer, quer pela riqueza originada pela diversidade do conjunto de ambientes geográficos e o nível de perfis profissionais a que pertencem os participantes dos Seminários.

\section{CONFLITO DE INTERESSES}

Os Seminários de Inovação em Cuidados de Saúde Primários contam com o apoio da Fundación Ciencias de la Salud, da Fundación para la Formación de la Organización Médica Colegial de España, e da Fundación Jordi Gol (Instituto de Investigación en Atención Primaria); os Seminários de Inovação em Cuidados de Saúde Primários recebem apoio financeiro do Ministério da Saúde de Espanha e o laboratório Glaxo SmithKline.

\section{REFERÊNCIAS BIBLIOGRÁFICAS}

1. Eurostat News Release: Regional GDP per inhabitant in the EU27, 19th February. disponível em: http://ec.europa.eu/eurostat [acedido a 25/02/2009].

2. Human Development Indices: a statistical update 2008 - HDI rankings. Disponível em: http://hdr.undp.org/en/statistics/ [acedido a 26/02/2009].

3. Simó Miñana JS, Gérvas Camacho J, Seguí Díaz M. Pablo Gonzáles R, Domínguez Velázquez J. El gasto sanitario en España en comparación con el de la Europa desarrollada, 1985-2001. La atención primaria española, Cenicienta europea. Aten Primaria 2004 Nov; 34 (9): 472-81.

4. Gérvas J, Pérez Fernández M. Western European best practice in primary healthcare. Eur J Gen Pract 2006; 12 (1): 30-3.

\author{
ENDEREÇO PARA CORRESPONDÊNCIA \\ Juan Gérvas \\ Travesía de la Playa 3, 28730 \\ Buitrago del Lozoya (Madrid), Espanha \\ E-mail: jgervasc@meditex.es
}

Recebido em 12/03/2009

Aceite para publicação em 15/10/2009

\section{ABSTRACT}

\section{INTERNATIONAL PERSPECTIVES; THE FAVOURABLE WINDS BLOWING FROM SPAIN AND THE EXPERIENCE OF THE PRIMARY HEALTH CARE INNOVATION SEMINARS}

The primary care innovation seminars are a unique initiative in the european stage of primary health care. It is organized jointly by three spanish organizations and coordinated by a general practitioner. The seminars foster the analysis of the latest trends and innovations in terms of the organization of health care services, clinical research, as well as the main issues that will embody family medicine in the 21 st century.

This initiative is of interest to portuguese primary care physicians and trainees, since the contact with this initiative caters for a considerable personal gain in terms of inherent discussion, production of knowledge and interaction with a dynamic spanish multidisciplinary network of primary health care professionals.

Key-words: Innovation; Primary Care; Network; Seminars; Spain. 